\title{
Community Leadership through Conversations and Coordination: the Role of Local Surveys in Community Foundation Run Community Indicators Projects
}

\author{
Frank Ridzi ${ }^{1,2} \cdot$ Trina Prior $^{3}$
}

Received: 28 February 2020 / Accepted: 23 October 2020/Published online: 04 November 2020

(C) Springer Nature Switzerland AG 2020

\begin{abstract}
Community indicators (CI) projects rely on a variety of sources for the data that they make available to measure community well-being. While statistics collected and distributed by national and local governments are perhaps the most prevalent, some communities in both Canada and the United States have found great advantages to commissioning or administering their own surveys of local community members in order to enhance the insights that government-curated data can provide. In this paper we examine two organizations engaged with indicator projects that have opted to do so from the perspectives of their primary CI project supporters: the Vancouver Foundation in Canada and the Central New York Community Foundation in the United States. Among the advantages explored are increased capacity in key community leadership elements of: engaging residents, working across sectors, commissioning and disseminating local data and research, shaping public policy, and marshaling resources. We conclude by reflecting on the many synergies between the CI and community foundation $(\mathrm{CF})$ movements, paying attention to their shared interests in community wellbeing through better conversations and coordination among the organizations in the communities they serve.
\end{abstract}

Keywords Community foundations · Community indicators · Community leadership · Surveys

Frank Ridzi

fridzi@cnycf.org

1 Central New York Community Foundation, Syracuse, NY, USA

2 Le Moyne College, Syracuse, NY, USA

3 Minerva BC, Vancouver, Canada 


\section{Introduction}

Community well-being is a multifaceted and interdisciplinary concept that invites a variety of frameworks as well as industry sectors to participate in its study and improvement (Phillips and Lee 2019). While a shared definition may be elusive, two key dimensions have helped to give shape to this growing field of study: 1. Indicators used to measure community well-being (Sung and Phillips 2018) and 2. Action being taken by local community members and anchor institutions to improve community well-being (Sirgy 2018). In the following pages we explore how two international movements, the community indicators (CI) movement and the community foundation (CF) movement, have characteristics that naturally position them to contribute to our understanding and improvement of community well-being. We then review how both movements have experienced increasing focus on local community well-being - CI increasingly focusing on localized data and CFs increasingly focusing on their deep knowledge of and ability to effectively take action to improve local communities. To further explore this increasing interest in local data and knowledge about community well-being, we then turn to two case studies where these movements have joined forces in the form of CF led CI projects, one in Canada and one in the United States.

We first provide context on the origin and development of these CF initiated CI projects before examining how their reliance on federally funded, and publicly available, data about their local communities proved insufficient to address the desire for knowledge about their local communities' well-being. We then profile innovative solutions to this problem and the new opportunities and capabilities local survey initiatives have created.

\section{Background and Literature Review}

Community well-being is a multifaceted concept that revolves around place and geography. It has historically been articulated in a variety of ways but often includes economic, social and physical community dimensions (Sirgy 2018). Though hard to define, there is general consensus that community well-being involves many interconnected parts that make it complex and hence well suited to interdisciplinary study in fields such as geography, sociology, political science and environmental and cultural studies (Phillips and Lee 2019). This has led to broad conceptualizations such as Kee et al.'s (2015) multidimensional model that includes the following six types of capital that a community can possess: human, economic, natural, infrastructure, cultural, and social (Lee and Kim 2018). Regardless of the dimensions included, community wellbeing is defined by the word "community" which typically refers to a specific local geography such as a city or town (Phillips and Lee 2019).

In addition to referencing a specific geography, two things that have historically been helpful in defining community well-being are: 1. Indicators and 2. Action. As we will explore in the future pages, both are points of synergy between the CF and CI movements.

\section{Indicators}

In the field of community well-being, indicators have been valued for their usefulness in "conceptualizing and assessing community wellbeing" (Sung and Phillips 2018). It 
is not until we begin to try to measure whether a community's well-being is high or low that we are faced with the many possible approaches we can take. Indicators help us translate our theoretical ideas into concrete, operational terms and force a degree of pragmatism on the study of well-being. After all, if well-being cannot be measured it is difficult to study using the standard tools of social science. The result is a robust literature on indicators of community well-being that is guided by such theoretical perspectives as "socio-economic development, personal utility, just society, human development, sustainability, and functioning" (Sirgy 2018:6, Ridzi et al. 2020). Rather than an afterthought, indicators and quality of life have evolved as intertwined concepts with some tracing the concept of quality of life and well-being itself to the US "social indicators movement" of the 1960s (Lee and Kim 2018:34).

\section{Action}

The goal of taking action to improve the well-being is another defining characteristic of the field of well-being studies. This is a goal as well for the CI movement (and as we shall see of the CF movement) but it is also part of a symbiotic relationship such that in the words of Sirgy (2018) "many community conditions are outcomes of community action (p. 4)." Hence action (or inaction as the case may be) is in many ways implied in the notion of indicators. Nevertheless, making the connection between indicators and action is itself a defining feature of the field as well-being and quality of life studies scholars have increasingly called for stronger connections between well-being studies and action in such forms as public policy (Lee and Kim 2018). This is another way in which well-being and indicators are interwoven. As Warner (2014) has pointed out, "A common thread among different indicator projects is the desire to find the right measures to influence policy and action (p. 45)."

The increasing focus on connecting the study of well-being with indicators-style measurement and action is most visible at the local level (Lee and Kim 2018). Some examples include Community Indicators Victoria (Australia), Jacksonville Indicators (United States), Sustainable Seattle (United States), Calgary Indices of Community Well-Being (Canada), and the World Bank's city indicators project (Lee and Kim 2018). Warner (2014) provides some further context to this local push for indicators and action by chronicling how the common frameworks that dominated quality of life studies (sustainability, healthy community, and government benchmarking) were augmented in the early 2000s with a more subjective approach to well-being in such forms as questions of happiness and public happiness. ${ }^{1}$ This focus on measures of subjective well-being opened the door to collecting data beyond typically collected and reported census-style data and government administrative records. As Sirgy (2018) has pointed out, CI projects seeking to capture residents' perception (such as happiness) and to assess the condition of community services have been forced to resort to community surveys. While requiring greater investment of local resources, it plays into one of the strengths of CIs in its emphasis on the local. As Warner has argued (2014), "from inception, the greatest strength of the community indicators movement was perhaps the

\footnotetext{
${ }^{1}$ Warner (2014) points to such instances as Bhutan's Gross National Happiness Index, the Organisation for Economic Cooperation and Transforming Data into Policy-Relevant Information Development's (OECD) Better Life Initiative, and the United Nations' (UN) World Happiness Report. “(p46-47).
} 
ability to hyper-localize measures of community well-being (p. 54)." In this increasing emphasis on the advantages of local focus and data granularity we see a parallel with the community foundation movement.

\section{The Community Foundation Movement}

What has been referred to as the "Community Foundation Movement" (Harrow et al. 2016; Sacks 2006, Community Foundation Atlas 2014²) is a parallel trend to the CI movement that has also occurred internationally (but with a large contingency in the United States and Canada). The CF movement focuses on action to improve community well-being. Recent years have seen growth in a variety of place-based funders (in the United States and globally) (Harrow et al. 2016; Mazany and Perry 2014:12) but CFs in particular have seen such massive expansion that nearly $75 \%$ of those that exist today were created in the last 40 years (Leonard 2014:108). Though CFs are known to play a variety of roles including investor, convener, partner, and supporter (Philipp and Traylor 2014:128), they can fundamentally be understood as charitable mechanisms designed, "to promote sustained community-based philanthropy and to address changing local needs (Walkenhorst 2010:7)." They do this mainly by soliciting donations, managing bequests and generally serving as a community's permanent charitable endowment that exists to invest donations wisely and using a prudent spending rate. Earnings are then reinvested back into the community through funding nonprofits to do work ranging from the arts and human services to animal welfare and environmental stewardship.

Dating back to $1914^{3}$ the CF movement in the United States has prospered from changes in tax laws that have given them advantages over private foundations and allowed for the proliferation of donor-advised funds (Harrow et al. 2016; Carson 2014:47; Leonard 2014: 108). The popularity of donor-advised funds effectively shifted the audience and accountability structure of CFs such that the majority of their business was living donors by the 1980s (Leonard 2014:108). This not only helped to drastically increase the number and size of CFs, but it also placed them in competition with forprofit financial sector products such as those offered by Fidelity Investments which allowed financial planners to also offer to help charity-minded citizens make donations back to their communities (Ballard 2007, Leonard 2014:108). As competition increased, CFs increasingly sought to articulate their market advantage as a profoundly more intimate knowledge of the local communities they serve (Harrow et al. 2016; Mazany and Perry 2014; Ballard 2007). A key part of this is a nuanced sensibility about the local needs and assets that together bring about the community's well-being and quality of life. Community Foundations have expressed that they have a 'finger on the pulse' of the local community in a variety of ways including the use of CI to monitor changes in community well-being in areas such as unemployment or teen pregnancy rates (Ranghelli 2006). However, one key area in which CFs have increasingly sought to distinguish themselves is in the area of community leadership (CFLeads and CFInsights 2017, Sacks 2014).

\footnotetext{
2 The Community Foundation Movement: http://communityfoundationatlas.org/

${ }^{3} \mathrm{https}$ ://www.clevelandfoundation100.org/foundation-of-change/invention/national-community-foundationmovement/
} 
Within the CF world, community leadership has taken many forms, but has historically been defined along the lines of: contributing actively to community discourse in a way that better informs the community, building strategic connections that help to broker local solutions to pressing problems, cultivating both donor and governmental resources to maximize funding for local solutions, fostering greater efficiency in problem solving by leveraging systems change through such forms as policy advocacy and greater local collaboration, and championing accountability through measuring impact and increased capacity (Ballard 2007). This has often translated into such CF activities as: "convening stakeholders around a common problem or issue; forging partnerships that leverage additional public or private resources; brokering new, fragile or even contentious relationships; providing needed training and technical assistance to nonprofits; speaking out and using the media to raise visibility and spur action on an issue; commissioning research and needs assessments to identify gaps in services; and collaboratively creating new institutions (Ranghelli 2006:3)." Community Foundation community leadership has also been increasingly seen in the area of supporting collective impact efforts to collaboratively address community problems through coordinated, multi-sector and data driven partnerships (Ridzi and Doughty 2017; Ridzi 2019).

Though CFs as a field have experienced increasing market pressures to move into the community leadership space, and have even been the target of public admonishments to lead, engagement has been inconsistent with less than a third engaging in this way (Harrow et al. 2016). This is in part due to wide variation in the proportion of discretionary grant making funds across organizations (which results in discrepancies across CFs in terms of their latitude to direct funds toward contemporary needs) (Pavey et al. 2012). There is also broad interpretation about what is meant by "community leadership" (Pavey et al. 2012). In some cases, it has meant talking a stand to be a force for civility and progress amid political chaos. This is the case with the Community Foundation for Northern Ireland, which focused on peace building by gaining the respect of different sectarian constituencies, and with the Community Foundation for South Sinai and the Maadi Community Foundation - both in Egypt - which publicly embraced goals related to revolution (Harrow et al. 2016). In other cases, community leadership has taken the form of efforts to revitalize chronically disadvantaged communities through "embedded philanthropy" and civic engagement (Karlström et al. 2009). This has been the case with such CFs as the Denver Foundation and Humboldt Area Foundation in California who have invested heavily in fostering local resident leadership (by funding block parties, neighborhood cleanups and advocacy) and including BIPOC representation in economic planning efforts, respectively. In still other cases, such as the London Community Foundation, community leadership has taken the form of partnering with media (in this case the Evening Standard news outlet) to launch the Dispossessed Fund in order to shine a light on issues affecting Londoners ranging from food poverty to gang violence to COVID-19 (Pavey et al. 2012; The London Community Foundation 2020). Another approach to community leadership that has won acceptance in the CF world is that of curating and publishing indicators of community well-being, such as the Toronto Community Foundation's Vital Signs which serves as a platform for advocacy toward improved services and policy change (Harrow et al. 2016).

Seeking to assert themselves as local community leaders with specialized local knowledge and personalized service (Leonard 2014) many CFs have made investments 
in data infrastructures that reinforce their brand and identity as having a finger on the pulse of community well-being. In taking on this role, is not uncommon for CFs to conduct surveys. For instance, the first CF to come into existence, the Cleveland Foundation, conducted surveys at its onset related to schools and criminal justice to help set its grantmaking agenda and raise its profile as a leader in the community (Sacks 2014). More recently, in 2012 and 2015, the Kalamazoo Community Foundation surveyed the local community on community issues and philanthropic behavior. ${ }^{4}$ In 2016 and 2017, the Berkshire Taconic Community Foundation launched a resident survey to assess community needs to give local community members the opportunity to provide perspectives "on key challenges and opportunities for improving lives." 5 Similarly, in 2016 the Saint Paul and Minnesota Foundation launched the "East Metro Resident Pulse," a vitality survey of three counties that is conducted every two years. ${ }^{6}$ Lastly, and perhaps most pertinent to this paper, going back to 2006 in Canada, the Community Foundations of Canada (CFC) coordinated Vital Signs reports of existing data (Sacks 2014), to which some foundations elected to add a survey component.

The above literature on the CI and CF movements suggest a growing synergy of shared interests in the well-being of the local communities where they serve. Their work is mutually advantageous and inherently compatible because they are both "movements" aimed at improving the local communities they serve through participation of local residents. Community Indicators and CFs furthermore offer the potential to complement each other's work by identifying issues of community concern and matching funding to address them, respectively. Furthermore, both movements have been gravitating toward a more intimate knowledge of their communities. In this respect, the synergy between $\mathrm{CI}$ and CFs is visible through their mutual interest in local community surveys. To better understand the appeal of this trend, we present two case studies of CFs using CI and local surveys to focus on community engagement.

\section{Case 1: Vancouver Foundation}

\section{The Program Context}

British Columbia is Canada's westernmost province, and with 5.71 million people, has the country's third highest population (Statistics Canada). Vancouver Foundation is Canada's largest CF and although named after the city of Vancouver, it is a provincial charity. It has been investing in communities since 1943 and through its more than 1800 endowment funds, has distributed more than $\$ 1$ billion throughout the province to charities in areas such as arts and culture, education, children and youth issues, environment, animal welfare, community health and social development.

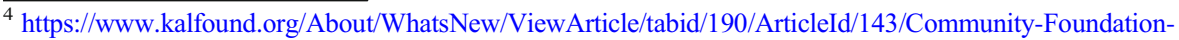
releases-community-survey-results.aspx

${ }^{5}$ https://www.berkshiretaconic.org/bLearnbAboutBTCF/BTCFNews/ViewArticle/tabid/96/ArticleId/1264/ Press-Release-Berkshire-Taconic-Community-Foundation-Launches-Resident-Survey-to-Assess-CommunityNe.aspx

https://www.berkshiretaconic.org/bLearnbAboutBTCF/BTCFNews/ViewArticle/tabid/96/ArticleId/1294/ Press-Release-Berkshire-Taconic-Community-Foundation-Releases-First-Ever-Regional-Assessment.aspx

${ }^{6} \mathrm{https} / /$ www.spmcf.org/what-we-do/invest-in-community-led-solutions/east-metro-pulse-report
} 
In addition to being a broad funder, the organization also focuses resources on community-identified initiatives that strengthen residents' connections and engagement in their communities. Vancouver Foundation works to convene partnerships and conversations around emerging issues, and also through conducting and sharing research. The commitment to learning and sharing knowledge and resources can be seen though its Open Licensing initiative ${ }^{7}$ which allows access to locally relevant and up to date data that can be used by others to identify and address the opportunities, issues and urgent needs related to their work.

Vancouver Foundation began its notable CI work in 2006 with the national launch of Vital Signs, ${ }^{8}$ a program which originated as a project of the Toronto Community Foundation in the late 1990's (Phillips et al. 2016), and is now coordinated nationally by Community Foundations of Canada (CFC). ${ }^{9}$

At the onset, the Vital Signs initiative was designed to focus on existing research from national, regional, government and non-government sources rather than conducting new research. Each report contained ten set issue areas, such as affordability, education and safety, with some CFs adding one or two areas specifically relevant to their community. Each issue area was then paired with four to ten indicators (Patten and Lyons 2009), with CFC providing CFs with national data sets. On a designated day in the first week of October, participating foundations across Canada would collectively launch their local Vital Signs reports.

Since its inception, "Vital Signs has evolved to become more flexible and accessible to a broad range of community foundations" (Pole 2015:6) with CFs adapting the format to ensure the best fit for their organization's needs and focus. Some have moved away from a comprehensive look at how communities are faring in a range of key quality of life areas in favor of releasing reports focused on a specific issue such as social capital and the creative workforce. Other foundations have elected to produce less labor-intensive mini reports or focus strictly on hosting community conversations. Most recently, CFC has begun to align national data sets with the UN's Sustainable Development Goals (SDGs) which has allowed CFs to measure local Canadian data against common indicators as well as in a global context. ${ }^{10}$

Vital Signs reports are designed to provide a comprehensive view of local issues and enhance the ability to make connections between various needs and issues. This allows CFs to work with a wide range of community stakeholders and sectors and is a means by which CFs can fulfill the community leadership aspect of their mission. With Vital Signs, CFs can play a role of neutral knowledge broker and convener in their community and are uniquely positioned to capitalize on their credibility to shape community discourse and dialogue on local issues (Pole 2015).

While CFC provides access to national data sets, many foundations also elect to complement existing data with a perceptions survey component. These surveys are administered locally by the host CF with many focusing on asking residents, or 'Citizen Graders', to assign a letter grade, or rating, to each issue area as well as identify top priorities that need to be addressed for the issue area.

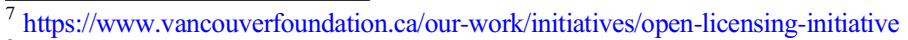

${ }^{8}$ For more information visit: www.vitalsignscanada.ca

${ }^{9}$ An umbrella organization for 191 community foundations operating across Canada

${ }^{10} \mathrm{https}$ //www.communityfoundations.ca/initiatives/vital-signs/
} 
Vancouver Foundation released its first report in 2006 with a focus on the City of Vancouver, an urban area with a population at the time of approximately 578,000 (2006 Statistics Canada). Three additional reports were released in 2007, 2008 and 2010 with an extended reach of metro Vancouver, an area with a population of approximately 2.5 million. Two special youth issues were released in 2009 and 2013. In 2016, the Foundation extended the reach of the report to have a provincial focus. The most recent report, released in October 2019, focused on community participation, ${ }^{11}$ and also has a provincial focus.

\section{The Limits of Publicly Available Data}

Although Vancouver Foundation's first Vital Signs report in 2006 relied heavily on secondary data, the foundation identified at the time that there were a number of frustrations with this approach including: not being able to find recent data; finding that necessary data had not been collected for certain areas of interest; discovering that data were not in a useable format; and issues with public accessibility. ${ }^{12}$ These frustrations were not isolated to the Vancouver Foundation. A report published in 2009 on the Vital Signs program acknowledged the challenge of obtaining sufficient and up-to-date data. As the authors concluded, "ultimately the contents of the reports are circumscribed by what data are available" (Patten and Lyons 2009:60). While working with CFC on the foundation's reports, Vancouver Foundation, in an approach used by other CFs, also collected local data through a research committee. Up until the 2010 report, survey data focused on assigning letter grades and identifying key areas for improvement, to provide valuable additional information to the report.

\section{Innovating with Local Surveys}

In 2016, Vancouver Foundation expanded its Vital Signs project to a provincial report to better reflect the foundation's geographic reach and to capture broader trends in communities throughout British Columbia. Due to the challenges of managing the scope of the project,and finding consistent and timely secondary data for both small and large communities, the decision was made to base the report solely on primary research collected through a survey. Working with Mustel Research Group, the survey contained three main areas of focus: 1 . community assets, which looked at what people liked best about their community; 2 . issue areas, which explored the issues of greatest concern and opportunity for improvement; and 3. sense of belonging and community involvement. In addition, there were 15 demographic questions including income, education, type of home/dwelling, ethnicity, personal family situation and years lived in current community to enable robust cross tabulation for Vancouver Foundation, and those wishing to use the data.

In addition to a research committee of local experts, the process of creating the survey was heavily influenced by input and feedback from other CFs, who were expected to be key users of the data. This process ensured it was relevant to, and representative of, the

\footnotetext{
${ }^{11} \mathrm{https}: / /$ vancouverfoundationvitalsigns.ca/

$12 \mathrm{https} / /$ www.vancouverfoundation.ca/sites/default/files/publications/Vancouver\% $27 \mathrm{~s} \% 20 \mathrm{Vital} \% 20 \mathrm{Signs} \%$ 20October\%202006_cc\%204.0.pdf
} 
diversity of the province's communities. Co-creation also fostered buy-in, which resulted in the majority of the province's CFs helping to distribute the survey ensuring provincial representation in responses.

The survey was completed online by close to $7100 \mathrm{BC}$ residents between June 14th and July 5th, 2016, far surpassing the initial goal of 5000 responses. The final sample was weighted to match Statistics Canada census data on the basis of gender, age, and region of residence. Community Foundations across British Columbia promoted the survey through websites, social media, email, newspaper advertisements and partnership arrangements. These valuable outreach efforts resulted in regional representation that otherwise would not have been possible. Approximately $70 \%$ of interviews were collected by Mustel Group through panels, and $30 \%$ by CFs. Respondents could complete the survey in English, Chinese, or Punjabi in an effort to further increase sample representation.

To ensure $\mathrm{CFs}$, and other interested parties, were able to view findings for the communities they serve, respondents were asked to identify where they live based on major centers where foundations are located. Respondents from smaller surrounding communities were asked to select the center they live closest to. Communities were then grouped into 'Regional Clusters' based predominately on BC Health Boundaries. ${ }^{13}$

\section{Case 2: Central New York Community Foundation}

\section{Program Context}

Syracuse New York is a medium sized city in the United States with a Metropolitan Statistical Area population of around 662,577. It is the largest city in the central New York region. The Central New York Community Foundation is the region's largest charitable resource. Established in 1927, it collects contributions from donors, manages them to grow over time and then distributes funding to local charities to help them thrive. With assets of more than \$280 million it has invested more than \$200 million in community improvement projects since its inception. As a grantmaker, civic leader, convener and sponsor of strategic initiatives, the Central New York Community Foundation strives to strengthen local nonprofits, encourage better understanding of the region, and address the most critical issues of our time. Syracuse traces its CI work back to 1997 when a group of citizens began to have community conversations, collect indicators and track progress (Ridzi 2017). This effort evolved in 2011 when the Central New York Community Foundation launched a new version of CI in a website format, CNY Vitals (Ridzi 2017). Today the website consists of two components that highlight key community trends in the areas of poverty, education, health, housing, economy and arts and people (or demographics). The first component is a data visualization engine whose construction and maintenance is contracted out to a firm, which routinely updates the database with publicly available statistics from sources such as the United States Census Bureau, the Department of Labor and the state departments of health and education. The second component is a website that takes selected data visualizations from the first web engine and embeds them

\footnotetext{
$\overline{13}$ https:/www2.gov.bc.ca/gov/content/data/geographic-data-services/land-use/administrative-boundaries/ health-boundaries
} 
on a more journalistically focused website that seeks to put a human face on the data available in the visualization engine. While both components are available on the internet and appear as companion websites, the visualization engine has a variety of complex permutations for data display options that are more suited to professional data consumers such as grant writers and program developers. The second, more journalistic website is designed for the general public who is seeking to keep tabs on key community trends and are more receptive to a curated interpretation of what these trends mean for people in their everyday lives and why it should matter to the reader.

This CI website is one of many that exist across the United States. It is similar in that the majority of data come from federally created sources that are made publicly available on government websites.

\section{The Limits of Publicly Available Data}

While the United States Census Bureau is a robust and essential national asset, when it comes to local community improvement there were several key shortcomings that led the Central New York Community Foundation to invest in greater local data collection infrastructure. First, was the issue of timeliness. As has been noted in other areas of the literature, the open source, free and easily accessible nature of government data comes with a trade-off of being delayed in its collection and availability. Sometimes data that are collected are not available for a year or more afterwards. This makes it very difficult for organizations to use these data for planning to address immediate needs, and also difficult to assess whether any progress is made after local CF funded action is taken. Furthermore, the audience for federal data is a national one that is satisfied with local estimates that have large margins of error. While this might be acceptable for communities that want to compare themselves with others across the nation, the error ranges are too large for communities that wish to use these data to measure themselves over time. Finally, the questions asked in the data collected by national government entities are uniform across the nation and unresponsive to the nuances of local questions for which community members are seeking answers. It is simply infeasible to expect federal data collection authorities to tweak their surveys and census mechanisms to more precisely probe the issues that are on the minds of today's Central New Yorkers.

Overdependence on publicly available data sources was a sense of frustration for residents of the Syracuse area. The community was able to identify where they were doing worse than other communities but not able to drill down to the specific sub parts or neighborhoods in the community to see what was going on at a more granular level. As a result, initiatives had major blind spots when it came to trying to deploy such approaches as Results Based Accountability (RBA) and Data Driven Decision Making (DDDM). Community leaders realized that, if they did not invest in a more sophisticated community data infrastructure, the majority of their day-to-day work would be conducted within a "black box "because they were unable to observe how things were progressing with data.

\section{Innovating with Local Surveys}

Given the shared desire for more intimate knowledge of the local community among both consumers of CI data and CF leaders, the Central New York 
Community Foundation took several key steps to invest in a better data infrastructure. The cornerstone of this investment was a local survey that it initiated in 2017. The foundation had been frustrated in the past by making investments using publicly available national data only to be thwarted in its efforts to measure and monitor progress using the same data sets (Ridzi 2012). Following investments in new staffing skilled in data analysis and program evaluation, the foundation was able to pilot more rigorous program evaluation of its literacy efforts and furthermore able to document its progress in changing not only the outcomes of program participants, but also neighborhood and community level data improvements (Ridzi et al. 2014; Singh et al. 2015; Ridzi et al. 2016). Emboldened by this success the foundation sought to build a similar infrastructure that could be used for other future programming and that could both reliably measure the efficacy of foundation grantmaking and empower local grant recipient partners and collective impact peers to achieve a data driven norm for decision-making, collaboration and ongoing refinement of efforts.

In collaboration with nonprofit partners participating in a data learning community the CF built a pilot for real time data sharing across organizations that would allow for coordinated, data driven action yet still protect the client confidentiality of all participating organizations (Ridzi 2020).

In simple terms, this platform consists of a set of commonly used community need and outcome metrics that were utilized across a series of nonprofit partners. The result was a series of new capabilities that strengthened the capacity of both the CI project and the $\mathrm{CF}$.

\section{Discussion: Leveraging Local Surveys for Community Leadership}

As with other CI projects internationally, the Central New York Community Foundation and Vancouver Foundation rely on a variety of sources to produce the data they publish related to community well-being. While statistics collected and distributed by national and local governments are cornerstones of the CI for these foundations, both have also found great advantages to commissioning or administering their own surveys of local community members in order to enhance the insights that government-curated data can provide. Among the advantages explored in these two comparative case studies are: increased relevance to local concerns, input from community stakeholders, timeliness, granularity to local geographies and the ability to incorporate local perceptions in telling the story of local communities. Each of these advantages are deployed to further the field by better measuring well-being and inspiring action but they do so in a way that is consistent with the broader CF field's aspiration of community leadership (CFLeads and CFInsights 2017, Sacks 2014, Ballard 2007, Ranghelli 2006). CFLeads (2019) has articulated five key elements of effective community leadership:

- "Engaging residents to hear their concerns, lift up their ambitions and harness their talents.

- Working across sectors because the challenges facing communities are multifaceted and inter-connected and cannot be solved by any one entity or sector. 
- Commissioning and disseminating local data and research to help understand the nuances of community challenges and provide information to help solve problems.

- Shaping public policy, recognizing that government systems have a significant impact on the lives of every resident.

- Marshalling resources beyond the foundation's own grants - from private foundations as well as from local, state and federal government - to address community needs (p. 1)."

As seen in Table 1 below, both of the CFs profiled have used local surveys to enhance their community leadership capacity in different areas. In the following sections we explore each initiative's efforts in greater detail so as to demonstrate the multiple ways in which surveys can be deployed to address different leadership goals.

\section{Engaging Residents}

Both CFs and CI exist in large part to serve the needs of a community's residents. This, however, has not always meant that residents have had a clear voice in the work of these institutions. Conducting a community survey can be one strategy for involving those who live within a community and incorporating their perspectives, concerns and ideas. In the case of Vancouver Foundation, engaging residents can be clearly seen in both the survey and community conversations which take place as a result of (or a precursor to) the report. In 2016, when the report was released, nine British Columbia CFs used the survey data and another 11 stated they planned use it the following year either through a report, community conversations or to inform their work.

Intentionally seeking to harness the talents of local residents, Vancouver Foundation's Open License policy provides opportunities for others to develop ideas, content, products, and services in ways that benefit the community and unlock the full value of resources such as Vital Signs. The contents of Vancouver Foundation's 2016 Vital Signs report were made available under this license, which applies to all of the data and means it can be used for other work, as long as Vancouver Foundation is credited as the source of the content.

Table 1 Overview of the community leadership capacity enhanced by local surveys

\begin{tabular}{lll}
\hline $\begin{array}{l}\text { Elements of Effective } \\
\text { Community Leadership }\end{array}$ & $\begin{array}{l}\text { Vancouver Foundation's } \\
\text { Vital Signs Survey }\end{array}$ & $\begin{array}{l}\text { Central New York Community Foundation's } \\
\text { Life Needs Assessment Survey }\end{array}$ \\
\hline $\begin{array}{ll}\text { Engaging Residents } \\
\text { Working Across Sectors }\end{array}$ & + & + \\
$\begin{array}{ll}\text { Commissioning and } \\
\text { Disseminating Local data }\end{array}$ & + \\
$\begin{array}{l}\text { Shaping Public Policy } \\
\text { Marshaling Resources }\end{array}$ & + \\
\hline
\end{tabular}


To further reinforce that survey data collected by Vancouver Foundation is intended as a community resource, the 2016 Vital Signs website was created in a way that allowed data to be easily downloaded and shared in a usable JPEG format. ${ }^{14}$

The Vital Signs survey results have helped Vancouver Foundation better understand the communities it serves, and in some cases has surfaced new priority areas. A suite of survey questions in 2010 helped to identify belonging as a focus which led to the expansion of a neighborhood grassroots granting program. ${ }^{15}$

Vancouver Foundation's Vital Signs projects are part of an ongoing commitment to understanding the priorities and experiences of community. It is used to inform and guide work as a funder, partner, and convener, and share it with organizations with the hope that it might create new opportunities from the data and findings.

In terms of increased input from community stakeholders, Warner (2014) has argued that, "Many early community indicator projects were driven by a desire to democratize data - to make information more available to the general public (54)." Such democratization is two sided in that it can mean both greater access to data and greater input to the focus and design of data collection.

For Vancouver Foundation, the creation of the first provincial survey in 2016 involved extensive input from community stakeholders. There was recognition that based on geography, economic conditions, and urban or rural setting, communities experienced different challenges and opportunities and had different needs in terms of usable data. A draft of the survey was created with input from an advisory committee of community stakeholders and was then shared with all British Columbia CFs for their suggestions and revisions. Not only did this approach result in a survey more reflective of the province, it served to increase use of the findings.

In 2019, when Vancouver Foundation sought to create a new provincial survey with a target focus on community participation, a decision was made to seek input earlier in the process. A half-day session was held with 50 participants comprised of individuals the Foundation had worked with before, as well as those who have never previously engaged with Vancouver Foundation.

From the workshop, four main areas were identified to focus on for the survey questions, along with assistance from the Mustel Research Group, questions were then crafted around the focus areas. They were then tested and revised with feedback and suggestions from staff, British Columbia CFs and a research advisory committee.

For the Central New York Community Foundation, resident engagement is more of an aspirational goal based on the approach of Human Centered Design (HSD). HSD is an approach to problem solving that keeps the human element of needs and assets at the core of the process and continues to circle back to people to be accountable to solving their problems (Harte et al. 2017; Bannon 2005). Because the survey collection data platform relies on collecting data directly from the clients of each participating nonprofit, rather than relying on the perspectives of nonprofit staff as had been prevalent in earlier times, the data are based on the real-time experiences of residents. As a result, when it comes time to plan policy or program related responses, participating organizations are equipped with the ability to rapidly identify which of their clients are experiencing specific needs and reach out to these clients to invite them to focus groups or other ways of sharing their personal insights. The

\footnotetext{
$\overline{14}$ https://2016.vancouverfoundationvitalsigns.ca/

${ }^{15}$ https://neighbourhoodsmallgrants.ca/
} 
result is a framework and infrastructure that facilitates human centered design - an emerging best practice that involves clients in the initial design of programmatic responses to their needs but then continues to engage them as future iterations and refinements to those programming responses are developed. Such programming efforts have historically taken shape within specific sectors and are siloed or disconnected from other sectors. For the Central New York Community Foundation, avoiding such disconnects has been an ambition from the launch of the local survey.

\section{Working across Sectors}

The idea of working across sectors has been at the heart of the national rise in popularity of collective impact and community coalition work (Ridzi and Doughty 2017). Inherent in this popularity is the recognition that communities face challenges that are not easy to solve. Oftentimes referred to as "wicked" social problems, they are multifaceted and interconnected such that individual sectors (such as schools, healthcare, government etc.) are unable to solve them on their own. This recognition was at the heart of the Central New York Community Foundation's local survey design and launch. In this case, it was a group of community stakeholders who first formulated and piloted the local survey (in collaboration with the Central New York Community Foundation). A member of the Adult Education Roundtable of the Literacy Coalition of Onondaga County shared an intake survey that they used with their clients with the group and this was later refashioned into the survey that was administered across all of the participating members in that roundtable group. This input allowed for a survey that was responsive to the needs of this group and inclusive of their primary concerns such as learning disabilities, educational attainment, and access to educational resources. However, it was also designed to be cross-sector and this has led to its uses as a match making tool across sectors.

Eventually the survey was adapted across nonprofits from a wide range of sectors ranging from hospitals to early childhood service providers, community centers and antipoverty programs. Because organizations were now sharing data in real time, while still protecting confidentiality, a new form of data-facilitated collaboration was possible. The Central New York Community Foundation allowed this network of cross-sector organizations to intentionally seek out opportunities to work across sectors through what came to be referred to as "Data Dating" (Ridzi 2020). This was a way for organizations to be much more specific in how they reached out to organizational partners. Rather than reaching out based on preconceived notions, organizations could now use data to identify other organizations that either had a shared need so that they could apply for grant funding together or a need that was complementary to an existing asset. For instance, an organization focused on job training could browse the needs of other organizations providing services such as food pantries etc. to find where there were many potential recruits for their programming. This would lead them to reach out to the organizations that were already serving those clients and test the waters for potential collaboration such as opening satellite sites, formalizing client referrals and other ways of rethinking how their different organizations and missions could complement one another.

Having a local survey has helped the Central New York Community Foundation to tell the stories of its communities not just from their perspectives, but also the perspectives of charities that were increasing their sophistication in the areas of working across sectors. As one shared, 
"Sometimes in Syracuse, organizations tend to work in silos and there are not always a lot of opportunities to meet and exchange ideas," one nonprofit survey participant said. "This provides us with an opportunity to all get to the table and examine through data how we can work through problems collectively."

Because the data collected by each organization were geocoded to census tracts before being anonymized and shared across organizations, the data could then be analyzed according to very granular neighborhood geographies. This allowed for an approach known as "hotspotting" in which key neighborhoods that were experiencing increases in particular needs could be identified and resources could be pulled together across organizations that were serving clients in the same neighborhood that experienced the acute needs. For instance, one neighborhood community center was able to use the data to plan a Community Day, to bring in agencies that provide services toward the greatest needs reported in their clients' assessments. As they shared, "When we evaluated the data that we and our... partners gathered, it became clear to us that we needed to double down on our food pantries," and "We found that there is a real need for food and personal items within some neighborhoods of the city, and we need to increase our efforts to get funding that will allow us to increase our supplies."

As the saying goes, all politics are local. The same can be said about community needs. Knowing about current needs is only part of the battle. Knowing where they are concentrated is another key point of data. In the words of the nonprofit that planned the community day, "This tool gives us opportunities, especially with live mapping, to identify locations where interventions can be made... Such an opportunity to identify unanticipated needs was so powerful and some partners were so surprised by what they found that they ended up using the data for strategic planning".

\section{Commissioning and Disseminating Local Data}

It is not uncommon for people seeking CI data to presume that certain data sets exist and are accessible only to be surprised when they are unable to find such data. Publicly available government data only go so far and, as a result, communities trying to address needs that arise from resident concerns find that they are not always able to rely on data to understand the nuances of their community.

The provincial survey, managed and funded by Vancouver Foundation, enabled CFs to use the survey data specific to their region to supplement the work they were already doing and pair it with local secondary data. For some of the smaller foundations, the survey research made it possible for them to take part in the initiative they otherwise would not have been able to. For instance, the Sunshine Coast Community Foundation, who had not intended to produce a report in 2016, received such a great response rate from their community, that they decided to publish a four page mini report ${ }^{16}$ with key findings from the region.

Community Foundation driven survey findings can serve as a source of free, unbiased research for citizens, local government, businesses and service providers to better understand their community and take action. It is a resource to help mobilize community knowledge and identify community priorities.

\footnotetext{
$\overline{{ }^{16} \text { https://www.sccfoundation.com/news/vital-signs-2016 }}$
} 
The survey component of the Vancouver Foundation work has evolved since the first report in 2006. For the first survey, Ipsos Reid Research firm was commissioned to conduct an omnibus survey with four quality of life questions. In total, a random sample of 240 Vancouver residents was polled through a telephone survey. This was combined with an online perceptions survey where close to 200 informed citizens, comprised of civic, nonprofit and business leaders, were asked to assign a letter grade and identify top priorities for the issue areas. Although the response rate increased in 2007 and 2008, when the report changed its reach to the larger metro Vancouver area, the approach remained the same with a random quality of life phone survey and a targeted online survey for citizen graders.

In 2010 the approach was simplified to have one comprehensive survey, conducted online, which included quality of life questions, grading for the issue areas and identification of top ways to improve the issue areas. The survey was distributed through Environics Research to their panels and received almost 1200 responses.

In 2016, the foundation had a desire to expand beyond metro Vancouver to a provincial survey. The reason for this was to provide a resource for the other $53 \mathrm{CFs}$ around BC to help with their Vital Signs projects. Although CFC provides access to existing supporting data, primary research is time consuming and expensive to collect, so by acting as a data collection point for the province, the information could be shared widely to provincial CFs to reduce costs and avoid duplication of effort. By taking this approach, Vancouver Foundation would be able to provide communities around the province with data tables for their area which could then be incorporated into, or used to supplement, Vital Signs projects. A second rationale was that, as a provincial funder, it was a way to better understand the communities served and to learn about regional differences, similarities, issues, and opportunities.

The creation of a provincial survey allowed Vancouver Foundation to provide regional and local data to all CFs in British Columbia. This was an important shift as it enabled CFs at a local level to use primary research in their own Vital Signs projects to tell the story of their community, which could then be paired with national data provided by CFC, or local sources such as libraries, municipalities or post-secondary institutions. Any community with a minimum response rate of 100 received the data tables for their area. In total, 22 communities achieved this number. Sixteen regional reports were also created, based geographically off the health regions in the province.

The expectation that each community collect a minimum of 100 surveys highlights a principle of "sweat equity" such that participants feel that knowledge and resource sharing are not one-sided. In the case of the Central New York Community Foundation, participating organizations were also required to collect 100 surveys before they were granted access to the data collected by other participating organizations. In both cases this expectation of sweat equity helped to fuel a larger network of data sharing that has the potential to inform communities about localized needs as they fit into a larger community context. This expectation of sweat equity as a form of positive peer pressure to collect data for the common good also highlights the lack of available data for the community and the niche that CFs can play by commissioning, championing and spearheading local data collection.

Timeliness is a key part of the value added of commissioning data collection. Vancouver Foundation launches its survey in late spring/early summer for the years it produces a Vital Signs report. The report is released the first week in October and 
community conversations often take place within six months of the release of the data. This increases the confidence of those consuming and using that data on current perceptions and actions of residents.

A key way that CFs can fulfill their leadership role is through convening and facilitating knowledge sharing. However, with limited time and resources, this can present a challenge for many looking to engage in this work. Vancouver Foundation was able to support capacity in this area by customizing tool kits of resources and data for use by the CFs in British Columbia.

A starting place for this work was hosting webinars and creating a document to help the foundations understand how to interpret the survey data, and further how it could be used. To assist further, Community Conversations toolkits were created. These were intended to allow CFs to use their local knowledge and connections to focus on the issues of most importance to them, while minimizing the time and effort required to host the events. The kits included: posters and social media promotional templates; customized data sheets for the area; conversation worksheets which included local data specific to the topics selected by the community, signage, copies of the report, and an event guide book. Foundations were also given a small grant to help with the costs of rental space, catering and audiovisual equipment.

Squamish Community Foundation was one of the foundations that utilized the toolkit to host a community conversation. The conversation was held in the spring with the goals for the event including a discussion on areas of concern, evoking positive change, and enriching the quality of life for Squamish residents (Green 2017). Information from the event was then used to help inform direction for their Vital Signs report which was set to release in October 2017. The capacity crowd at the event included the mayor and local experts who moderated the table discussions on key concerns such as housing and youth engagement. Basing the conversations around the survey findings for the area was highly valuable for the community as it enabled a data-centered discussion rather than speculation on top resident concerns.

In the case of the Central New York Community Foundation, data sharing is done more on the network level (i.e. organizations that participate in the survey are able to see each other's data but those outside of this group do not have access). For these groups, timeliness and specificity to their clients' needs are paramount. Previous experiences with long delayed data have haunted the Central New York community and made it challenging to feel as though community efforts were responding to the here and now, rather than to last year's problems that we were just hearing about now. The difference was quite noticeable once the survey was launched. Several nonprofits, as well as the Central New York Community Foundation, noted increasing need in such things as food insecurity in real time and had conversations about these internally before talking about potentially collaborating to take action. By the time such groups connected they were already thinking about what other organizations to reach out to for collaboration.

\section{Shaping Public Policy}

Community Foundation and CI initiatives are both often quite aware that they cannot solve the social problems they focus on by themselves. In the case of CI projects, there 
is a realization that the major goal is to identify and bring awareness to community needs, and then to hand off the work of addressing those needs to other community actors. For CFs, the role may include identifying funding needs and raising awareness but then extend into funding pilot projects and collaborations or collective impact coalitions to work on addressing those needs. However, even in these cases there is an awareness that foundation resources are limited and insufficient to address wicked social problems without the involvement of government.

Governments have access to a variety of data sources that CI projects and CFs do not. However, the form and format of these data are typically mandated by federal and state/ provincial source so governments, even local governments, seldom have time to explore the nuances of local needs through conducting local surveys. In the case of the Central New York Community Foundation, the local survey helped to bolster efforts to shape public policy pertaining to lead poisoning. The Central New York Community Foundation run CI project (CNY Vitals) revealed that lead exposure among children was three times higher in the county as compared to neighboring counties. However, these publicly available data were several years delayed in being released and they were not nuanced enough to understand the dynamics behind this problem. After reviewing more recent administrative data on lead exposure, the local survey being administered was able to probe deeper by asking about whether people had their homes or children tested for the presence of lead. Noting a high proportion of families indicating that they were not being tested and noting this was increasing in real time provided confidence that this was a problem that was far from solved. Furthermore, it was of a magnitude that could not be addressed with limited CF funding. As a result, the foundation took a role in actively supporting policy change in the form of a city ordinance to make testing for the presence of lead a requirement for rental apartments. This would solve the problem of people not having their homes tested. With the passing of this ordinance on July 13, 2020 this change in government systems promises to have an impact on the lives of residents that will extend far beyond the limited resources at the disposal of the foundation.

In addition to directly advocating for government policy change, CI and CFs can leverage local surveys to address the systems by which governments get their work done. Government systems involve both formal government and the many nonprofits they contract with to carry out direct service delivery. In the case of the Central New York Community Foundation's work in Syracuse, a close dialogue with the city about lead exposure and what to do once lead was discovered revealed that there was a dearth of local contractors that were trained in safe renovation practices in buildings that contain lead (potentially resulting in them making the problem worse by spreading contaminants in the midst of renovation). Pairing the survey with collaborative relations in this way helped to reinforce that there was a real time need and encouraged collaboration and mutually supportive relationships that offered momentum as the city and county successfully applied for over $\$ 9$ million in federal U.S. Department of Housing and Urban Development (HUD) funding. The work of foundations in this arena can be less visible and more behind the scenes. This does not mean it is not impactful. This is indeed the case in Syracuse since federal officials shared that the foundation's work on bringing attention to this area and committing funding was influential in the federal government's decision to provide funding. The ability to help attract funding brings into focus the critical work of marshaling resources that we discuss in the following section. 


\section{Marshaling Resources}

Attracting funding to the community to address community needs is only half the battle. Strategizing a plan, orchestrating that plan, and tracking progress involve critical components of follow through and can leverage local surveys. Marshalling involves the steps taken to "bring people or things together and organize them so that they can be used in an effective way" including work to "organize information or ideas." survey has been helpful in marshalling resources around dealing with concentrated poverty by providing insights into community conditions and the success in addressing them.

As a community, residents were actively discussing a report that had ranked the community as among the worst in the United States for concentrated poverty. While this alone was sufficient to create robust civic discussion, the community lacked data that allowed for probing the different dimensions of this local concern. Poverty is an abstract concept. Once addressed in the local survey that was created, however, it was possible to break the experience of poverty down into a variety of categories including housing, transportation, healthcare, clothing etc. Being able to focus on this area of local concern also helped the foundation to feel more confident in its grant making and more responsive to the nuances of local need. As Sirgy (2018) has asserted, CI projects can take a variety of different value propositions ranging from focusing on sustainability and social cohesion, to social inclusion and empowerment. In this case another of the dimensions he notes, socio-economic security, took first priority.

Having a local survey also helped the community to take a Results Based Accountability (RBA) approach to handling the over $\$ 30$ million in state funding that it successfully attracted to deal with poverty. While the Central New York Community Foundation, and key partners such as the county government, had been interested in pursuing RBA, program evaluation level data that could be combined across programs to monitor population level change was difficult to come by. As a result of this new local survey, administered continuously and online, a new source of data emerged that could be aggregated and could then be used to anticipate changes in other more longterm indicators. In one example, programs that received state anti-poverty funding were expected to have their clients complete the local community survey to both notice trends across clients of different organizations (i.e. declining unmet needs is a positive indicator along the pathway out of poverty) and notice opportunities for cross sector collaboration (as described above). In another instance, organizations that received funding were required to keep track of the people they served and to identify them by geographical location (census tract). This resulted in the ability to conduct program evaluation in new and innovative ways that were consistent with RBA. For instance, one organization reported significant numbers of clients who were provided transportation services in a select group of census tracts. It was then possible to examine surveys collected in the targeted census tracts and monitor as the reported need for transportation declined.

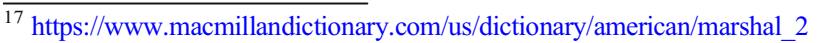




\section{Lessons Learned for Other Communities}

The experiences of the Vancouver Foundation and the Central New York Community Foundation offer insights for other CFs that are considering investments in local surveys as part of a CI and community leadership strategy. Specifically, such surveys offer a tool for conversations and coordination that can help a CF strengthen their portfolio in any of the five key elements of effective community leadership that CFLeads (2019) has identified. When it comes to engaging residents, both examples offer helpful insights in their differing approaches. The Vancouver Foundation targeted the community at large through publically disseminated surveys and this has helped them emerge with a general sense of the opportunities and concerns of citizens across all walks of life. However, this approach is most likely to miss the dispossessed and hardest to reach citizens who most lack a voice. That is precisely the population with which the Central New York Community Foundation sought to connect. In their case, residents had to be a client of organizations that tended to serve those in greatest need in the community. Community Foundations seeking to engage residents would do well to be clear at the outset about what parts of the population they are seeking to engage. When it comes to working across sectors, surveys can be effective at identifying what sectors should be involved and at gauging the relative magnitude of sentiments and needs. The Central New York Community Foundation began with a mature survey from the human services sector which allowed it to assess the prevalence of multifaceted needs that the human services sector had already established were present (for instance the survey did not just ask about poverty but about the multiple dimensions of poverty). In addition, in order to enable cross-sector collaboration, organizations had to buy in to conducting surveys in which the majority of questions did not pertain to the services they offered (although they were welcome to augment the survey with such questions). Only by asking residents about the needs that their services do not provide for could they learn what other sectors they needed to coordinate with.

Both foundations offer instructive lessons when it comes to commissioning and disseminating local data and research to elucidate the nuances of problems. Neither foundation is yet fully leveraging local surveys to the full capacity of addressing all five community leadership components. This is partly a function of time; these communities may eventually evolve to utilizing local surveys to bolster their portfolios in all five elements. It is also a function of the fact the local surveys incur costs that must be balanced with the realities of finite resources. These include not only the costs of doing the survey work itself, but the time and resources needed to deal with the complexity of coordination with partner stakeholders. In recognition of the high cost of conducting surveys, the Vancouver Foundation views funding a provincial survey as one of the ways it can support and help build the capacity of other CFs in the province to take on their own data based projects. While the Central New York Community Foundation supports nonprofits in administering their own surveys, this is not without its own cost to staff time. However, because it aligns with strategic plan goals (i.e. capacity building efforts among nonprofits), much of this work is done in a collaborative learning community setting with nonprofits focused on improving performance management skills, which helps to justify the use of staff time.

When it comes to the complexity of coordination with partner stakeholders, Vancouver Foundation has found that those aged 18-24 can be a challenging group to reach for survey participation. In order to achieve a representative sample for 
Vancouver Foundation's 2019 provincial survey, social media boosts were purchased for Facebook and Instagram, extra outreach efforts were conducted with youth serving organizations to distribute the survey and an additional youth panel was accessed through Mustel Research Group. Province-wide representation would not have been possible strictly through typical research panels which tend to have representation from the larger centers. Outreach by CFs in the province helped to address this issue. Taken together, this enterprise, like many community initiatives, moves at the speed of trust. For both communities, the survey efforts started small and began to grow in the fashion of a snowball as they gained momentum over time.

In the area of shaping public policy, local surveys can be very helpful as the source material for public policy advocacy, white papers and complex policy discussions. The added specificity and real-time nature can also provide assurances that the foundation is directing its advocacy at the optimal policy levers that will address community needs or build on strengths and talents. Finally, surveys can help with marshalling resources because they offer a specificity about community issues that is not often available in publically collected data. Just as importantly, they offer moveable numerical targets (such as the percent of respondents that report a specific need such as transportation) that donors and other partners can all unite their resources around.

\section{Conclusion}

Focus on the creation and use of local surveys highlights some of the key synergies between the $\mathrm{CI}$ and $\mathrm{CF}$ movements. It also helps to add new perspective to the already interdisciplinary study of community well-being. The CF and CI movements intersect and find synergies in their shared love of place and passion for location. But beyond their shared interest in the local communities where they are anchored, they both seek community engagement through conversations and better coordination among local stakeholders. It is in service to this ideal that we see such strategies as resident engagement, commissioning data collection, data dating and co-creation of shared metrics to facilitate collective impact and results-based accountability. Coordinated CI projects and CFs serve to raise each other's profiles and mutually reinforce each other's missions. Furthermore, they have a symbiotic relationship in that Cl's address the CF need for community knowledge to invest in projects focused on well-being while CF's offer a steady source of funding for CIs.

Both CI projects and CFs see mission overlaps when it comes to striving for expertise in the areas of: 1- Knowing the community, 2- Long-term focus and 3- Results driven learning organizations that seek to evaluate impact. As Mazany and Perry (2014) point out, CFs are increasingly carving out their market niche in relation to their specialized local knowledge and personalized service. When comparing them to other philanthropic mechanisms, the distinguishing factor of CFs is in knowing the community (CFLeads 2013).

Community Foundations tend to be results-driven learning organizations that seek to engage in and evaluate the impact of their community leadership work (CF Leads 2013:3). In this article we have explored this within the framework that CFLeads (2019) has articulated around the five key elements of effective community leadership. We have focused on how the two CFs studied have leveraged a local survey component to their CI work in order to improve their competency for these elements. Specifically, we explored 
how a local survey can foster better engagement with residents around their concerns and the ways their ambitions and talents can point us toward solutions. We have seen how surveys can enable the service delivery community to work across sectors and we have seen how surveys can position foundations to originate and disseminate local data that can provide insights into the nuances of community challenges. All of this work empowers CFs to have a confident voice and to speak up in the service of shaping public policy; and more strategically to help in marshaling local resources.

As Slutsky and Hurwitz (2014) assert, "community foundations raise the patient capital that allows them to stick with issues, even difficult ones, over the long haul. Entrenched poverty and environmental degradation will not be solved during our lifetimes. Fixing the schools, creating jobs for all who need them, and reforming healthcare will take years of hard work and perseverance - and reliable, patient capital. It's no accident that philanthropy often focuses on "intractable" problems (p. 85)." By focusing on identifying and then deepening understanding of such social problems through local surveys, CFs and CI strategically invest in detailed knowledge that can empower the communities they serve to take data driven action. They further reinforce the nexus of their missions by strengthening the leadership roles they play in monitoring and improving community well-being.

Data Availability Not applicable.

\section{Compliance with Ethical Standards}

Conflict of Interest 'Not applicable'.

Code Availability 'Not applicable'.

\section{References}

Ballard, C. S. (2007). Community foundations and community leadership. CFLeads Community Leadership Series Number 1 August 2007. Retrieved July 19, 2020 from http:/www.philanthropy.org/seminars/ documents/CFLeads.pdf

Bannon, L. J. (2005). A human-centred perspective on interaction design. In A. Pirhonen, P. Saariluoma, H. Isomäki, \& C. Roast (Eds.), Future interaction design. London: Springer.

Carson, E. (2014). The future of community foundations. In T. Mazany \& D. Perry (Eds.), Here for good community foundations and the challenges of the 21st century (pp. 43-58). New York: M.E. Sharp.

CF Leads. (2013). "Framework for Community Leadership by a Community Foundation." Created by the National Task Force on Community Leadership Prepared by CFLeads and Aspen Institute Community Strategies Group Retrieved April 23, 2017 from https://cfleads.org/wp-content/uploads/2019/10/ CFLeads-Framework-1.pdf

CFLeads (2019). Elements of effective community leadership. https://cfleads.org/wp-content/uploads/2019/12/ FiveCompetencies.pdf

CFLeads \& CFInsights. (2017). Assessing community foundation needs and envisioning the future. Retrieved from http://www.cfinsights.org/Knowledge/Overview.aspx

Community Foundation Atlas. (2014). Dimensions of the field: An in-depth analysis of the community foundation movement.

Green, M. (2017). Connecting the dots with conversation: Squamish will discuss areas of passion and concern. April 19, 2017. The Squamish Chief. https://www.squamishchief.com/community/connecting-the-dotswith-conversation-1.16050215.

Harrow, J., Jung, T., \& Phillips, S. (2016). Community foundations: Agility in the duality of foundation and community. The Routledge companion to philanthropy, pp 308-321. 
Harte, R., Glynn, L., Rodríguez-Molinero, A., Baker, P. M., Scharf, T., Quinlan, L. R., \& ÓLaighin, G. (2017). A human-centered design methodology to enhance the usability, human factors, and user experience of connected health systems: A three-phase methodology. JMIR Human Factors, 4(1), e8. https://doi.org/10.2196/humanfactors.5443.

Karlström, M., Brown, P., Chaskin, R., \& Richman, H. (2009). Embedded philanthropy and the pursuit of civic engagement. The Foundation Review, 1(2). https://doi.org/10.4087/FOUNDATIONREVIEWD-09-00016.

Kee, Y., Kim, Y., \& Phillips, R. (2015). Modeling community well-being: a multi-dimensional approach. In Y. Kee, Y. Kim, \& R. Phillips (Eds.), Learning and community approaches for promoting well-being (pp. 1-16). Switzerland: Springer International Publishing.

Lee, S. J., \& Kim, Y. (2018). Economy Doesn't buy community wellbeing: A study of factors shaping community wellbeing in South Korea. Int Journal of Com WB, 1, 33-44. https://doi.org/10.1007/ s42413-018-0004-2.

Leonard, J. (2014). Merging money and mission: Becoming our community's development office. In T. Mazany \& D. Perry (Eds.), Here for good community foundations and the challenges of the 21st century (pp. 107-122). New York: M.E. Sharp.

Mazany, T., \& Perry, D. (Eds.). (2014). Here for good community foundations and the challenges of the 21st century. New York: M.E. Sharp. https://117.211.153.211:8001/jspui/bitstream/123456789/236/1/ 0765642557.pdf.

Patten, M., \& Lyons, S. (2009). Vital signs: Connecting community needs to community philanthropy in Canada. The Philanthropist, 22, 56-61.

Pavey, H., Harrow, J., \& Jung, T. (2012). The role of community foundations in the big society: Taken for granted? In Philanthropy and a better society. Alliance Publishing Trust. https:/cfleads.org/wp-content/ uploads/2019/10/CFLeads-Framework-1.pdf

Philipp, A., \& Traylor, T. (2014). Ensuring there is "community" in the Community Foundation. In T. Mazany \& D. Perry (Eds.), Here for good community foundations and the challenges of the 21st century (pp. 123-130). New York: M.E. Sharp.

Phillips, R., \& Lee, S. J. (2019). Int. Journal of Com. WB, 2, 79. https://doi.org/10.1007/s42413-019-00032-y.

Phillips, S., Bird, I., Carlton, L., \& Rose, L. (2016). Knowledge as leadership, belonging as community: How Canadian community foundations are using vital signs for social change. The Foundation Review, 8(3). https://doi.org/10.9707/19944-5660.1314.

Pole, N (2015) Vital Signs: An exploratory case study of community foundations' local collaboration in a National program context. LMRPC-MRLCP. LaboMTL - Working Paper \#8. 1-71. https://philab.uqam. ca/wp-content/uploads/2018/01/Pole_2015_vital_signs_case_study_on_collaboration.pdf

Ranghelli, L. (2006). How community foundations achieve and assess community impact: Implications for the field. In L. Ranghelli, A. Mott, \& E. Banwell (Eds.), Measuring community Foundations' impact. Nonprofit sector research fund working paper series. Washington, DC: The Aspen Institute https:// www.michiganfoundations.org/sites/default/files/resources/CF-Measuring-Community-FoundationsImpact-NSRF-Aspen.pdf.

Ridzi, F. (2012). Managing expectations when measuring philanthropic impact: A framework based on experience. The Foundation Review, 4(4), 98-109.

Ridzi, F. (2017). Community indicators and the collective goods criterion for impact. In M. Holden, R. Phillips, \& C. Stevens (Eds.), Community quality-of-life indicators: Best cases VII (pp. 35-52). New York: Springer.

Ridzi, F. (2019). Collective action, collective impact and community foundations: The emerging role of local institution building in an era of globalization and declining social safety nets. In M. A. Fallov \& C. Blad (Eds.), Social welfare responses in a neoliberal era policies, practices, and social problems (pp. 137-159). Leiden, BRILL. https://doi.org/10.1163/9789004384118.

Ridzi, F. (2020). Goldilocks data-connecting community indicators to program evaluation and everything in between. In F. Ridzi, C. Stevens, \& M. Davern (Eds.), Community quality-of-life indicators best cases VIII (pp. 15-35). Switzerland: Springer. https://doi.org/10.1007/978-3-030-48182-7.

Ridzi, F., \& Doughty, M. (2017). Does collective impact work? What literacy coalitions tell us. Lanham: Lexington Books/Rowman \& Littlefield.

Ridzi, F., Sylvia, M., \& Singh, S. (2014). The imagination library program: Increasing parental reading through book distribution. Reading Psychology, 35(6), 548-576. https://doi.org/10.1080/02702711.2013. 790324.

Ridzi, F., Sylvia, M., Qiao, X., \& Craig, J. (2016). The imagination library program and kindergarten readiness: Evaluating the impact of monthly book distribution. Journal of Applied Social Science, $11(1), 11-24$. 
Ridzi, F., Stevens, C., \& Davern, M. (Eds.). (2020). Community quality-of-life indicators: best cases VIII. Switzerland: Springer. https://doi.org/10.1007/978-3-030-48182-7.

Sacks, E. (2006). Community foundations: Symposium on a global movement- Current issues for the global community foundation movement informed by knowledge shared and lessons learned. Worldwide Initiatives for Grantmaker Support (WINGS). https://cdn.ymaws.com/www.wingsweb.org/resource/ resmgr/files/cfsymposium.pdf

Sacks, E. (2014). The growing importance of community foundations. Indianapolis: Indiana University Lilly Family School of Philanthropy Retrieved on July 19, 2020 from https://philanthropy.iupui.edu/files/file/ the growing importance of community foundations-final reduce file size 2.pdf.

Singh, S., Sylvia, M., \& Ridzi, F. (2015). Exploring the literacy practices of refugee families enrolled in a book distribution program and an intergenerational family literacy program. Early Childhood Education Journal, 43(7), 37-45.

Sirgy, M. J. (2018). What types of indicators should be used to capture community well-being comprehensively? Int. Journal of Com. WB, 1, 3-9. https://doi.org/10.1007/s42413-018-0002-4.

Slutsky, L. A., \& Hurwitz, A. F. (2014). Future shock: the case for endowment. In T. Mazany \& D. Perry (Eds.), Here for good community foundations and the challenges of the 21st century (pp. 85-92). New York: M.E. Sharp.

Sung, H., \& Phillips, R. G. (2018). Indicators and community well-being: Exploring a relational framework. Int. Journal of Com. WB, 1, 63-79. https://doi.org/10.1007/s42413-018-0006-0.

The London Community Foundation. (2020). "Evening standard dispossessed fund." Website retrieved on July 25, 2020 from https://ondoncf.org.uk/partnerships/esdf

Walkenhorst, P. (Ed.). (2010). Building philanthropic and social capital: The work of community foundations. Gütersloh: Verlag Bertelsmann Stiftung.

Warner, J. Benjamin. 2014. The future of community indicator systems. In Federal Reserve Bank of San Francisco \& the Urban Institute (authors). What Counts: Harnessing Data for America's Communities, pp 45-57. http://www.whatcountsforamerica.org/portfolio/the-future-of-community-indicator-systems/

Publisher's Note Springer Nature remains neutral with regard to jurisdictional claims in published maps and institutional affiliations.

Frank Ridzi, PhD, MPA, is Vice President for Community Investment at the Central New York Community Foundation, Associate Professor of Sociology at Le Moyne College and President of the Board of Directors for the Community Indicators Consortium. Frank has helped to launch and lead community initiatives in areas such as increasing community literacy, reducing lead poisoning and addressing poverty and economic inclusion. He has been involved in launching Community Indicators efforts and has conducted research and written in the areas of collective impact, sociology of work, social policy and student affairs. His writings have appeared in such places as the Foundation Review, the Journal of Applied Social Sciences, the Journal of Organizational Change Management, and Review of Policy Research. He is a past President of the Literacy Funders Network, an affinity group of the Council on Foundations.

Frank holds a Masters Degree in Public Administration and a Ph.D. in Sociology from Syracuse University's Maxwell School. He also carries a Certificate of Advanced Study in Women's Studies. Prior to joining the Community Foundation, he served as Director for the Center of Urban and Regional Applied Research at Le Moyne College, where he still serves as Associate Professor of Sociology.

Trina Prior, MPNL, is the former Manager of Partnerships \& Community Initiatives at Vancouver Foundation, one of Canada's largest community foundations. Her work at the Foundation focused on community engagement, research and granting. She worked on the 2010, 2016 and 2019 Vital Signs reports, as well as the 2017 Connect \& Engage report.

Prior to joining Vancouver Foundation, Trina worked for 10 years at BC Children's Hospital as an educator for the injury prevention program before transitioning into fundraising at the Foundation. She is currently the Director of Partnerships and Engagement at Minerva BC.

She holds a Master of Philanthropy and Nonprofit Leadership from Carleton University in Ottawa, Canada, as well as a graduate diploma in Social Innovation from the University of Waterloo and a BA in Communication from Simon Fraser University. She is a member of the Board for ANSER-ARES, Association for Nonprofit and Social Economy Research (ANSER) - Association de recherché sur les organisms sans but lucrtif et de l'economie sociale (ARES). 